\title{
Electrochemical hydrogenation of nanocrystalline face-centered cubic Co powder
}

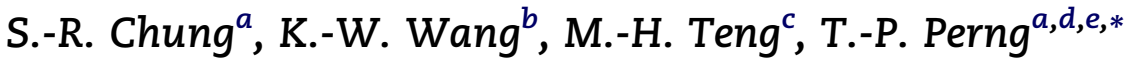 \\ ${ }^{a}$ Department of Materials Science and Engineering, National Tsing Hua University, 101 Sec. 2, Kuang-Fu Road, Hsinchu 300, Taiwan \\ binstitute of Materials Science and Engineering, National Central University, Chungli 320, Taiwan \\ ${ }^{c}$ Department of Geosciences, National Taiwan University, Taipei 106, Taiwan \\ ${ }^{\mathrm{d} D e p a r t m e n t}$ of Chemical Engineering and Materials Science and Engineering, Yuan Ze University, Chungli 320, Taiwan \\ eFuel Cell Research Center, Yuan Ze University, Chungli 320, Taiwan
}

\section{A R T I C L E I N F O}

Article history:

Received 4 December 2007

Received in revised form

20 August 2008

Accepted 29 November 2008

Available online 3 January 2009

Keywords:

Electrochemical hydrogenation

Co

Discharge capacity

FCC

$\mathrm{HCP}$

\begin{abstract}
A B S T R A C T
Nanocrystalline face-centered cubic (FCC) Co powder encapsulated within graphite layers was fabricated by an arc discharge method. Its electrochemical hydrogenation properties were investigated and compared with those of the hexagonal close packed (HCP) structure. Both exhibited a similar stabilized discharge capacity of approximately $350 \mathrm{mAh} / \mathrm{g}$ that can be attributed to the $\mathrm{CoH}_{x} / \mathrm{Co}$ reaction. During the cyclic charge/discharge, transition between HCP-Co and FCC-Co took place. Graphite encapsulation was beneficial to the cycle stability of the FCC powder.
\end{abstract}

(c) 2008 International Association for Hydrogen Energy. Published by Elsevier Ltd. All rights reserved.

\section{Introduction}

There has been an intensive effort to search for new materials with high hydrogen storage capacity and good retention of capacity for hydrogen energy application in the last several decades, such as alkaline metal aluminum hydride [1], LiN [2], metal-organic frameworks (MOFs) [3], metal-CNT [4,5], Co-Si $[6,7]$, and so on. Until now, only $\mathrm{AB}_{5}$-type hydrogen storage alloys have been often used as an anode material in secondary $\mathrm{Ni}-\mathrm{MH}$ battery. However, the theoretical hydrogen storage content of this type of alloy is only approximately $1.5 \mathrm{wt} \%$, and the discharge capacity of commercial alloys is between $250 \mathrm{mAh} / \mathrm{g}$ and $330 \mathrm{mAh} / \mathrm{g}$ [8-11]. A small amount of Co is commonly added to the electrode to reduce the volume expansion of the alloy during repeated hydrogenation/dehydrogenation or to form a conductive layer on the alloy surface $[12,13]$.

It has been recently reported that ultrafine amorphous boron-containing Co powder prepared by chemical reduction has a higher and more stable discharge capacity than that of traditional hydrogen storage alloys [14-16]. It was proposed that amorphous Co powder could absorb much hydrogen by replacing the residual boron in interstitial sites with hydrogen atoms. Feng et al. also pointed out that the CoB provided good electrochemical catalytic activity for MgNi alloy [17]. Previously, we have observed that boron-free crystalline Co could absorb electrochemically a large amount of hydrogen, and the discharge capacity was attributed to the $\mathrm{CoH}_{x} / \mathrm{Co}$

* Corresponding author. Department of Materials Science and Engineering, National Tsing Hua University, 101 Sec. 2, Kuang-Fu Road, Hsinchu 300, Taiwan. Tel.: +886 3 5742634; fax: +886 35723857.

E-mail address: tpperng@mx.nthu.edu.tw (T.-P. Perng).

0360-3199/\$ - see front matter @ 2008 International Association for Hydrogen Energy. Published by Elsevier Ltd. All rights reserved. doi:10.1016/j.ijhydene.2008.11.073 
dehydrogenation reaction [18]. Crystalline Co has two kinds of structure, HCP and FCC, and they have different gas-phase hydrogenation properties. The phase transition temperature between the low-temperature HCP phase and high-temperature FCC phase at ambient pressure is $450^{\circ} \mathrm{C}$. In gas-phase hydrogenation, the dissolution of hydrogen in Co stabilizes the HCP phase up to $\mathrm{CoH}_{0.6}$ at pressures below $2.5 \mathrm{GPa}$ [19]. When increasing the hydrogen pressure, the HCP-Co will transform into FCC-Co and the hydrogenation capacity also increases to $\mathrm{CoH}_{1.0}$. In electrochemical hydrogenation, the hydrogen fugacity is high enough so that reversible phase transformation between HCP and FCC may take place at room temperature. Therefore, Co hydride in the forms of $\mathrm{CoH}_{1.0}$ and $\mathrm{CoH}_{x}(x<1)$ may coexist.

In a previous work, we described that a crystalline HCP-Co powder containing a small amount of FCC-Co had a discharge capacity close to that of pure HCP-Co [18], and both the crystalline boron-free Co powders showed higher discharge capacities than that of amorphous $\mathrm{CoB}_{x}$ [16]. In general, it is not easy to prepare Co powder with a pure FCC structure because it is unstable at ambient temperature. It has been revealed, however, that FCC-Co can be encapsulated within carbon and remains stable at room temperature [20]. This paper describes the electrochemical hydrogenation property of such an FCC-Co powder that was used as the negative electrode material and tested in a battery system. The discharge performance is compared with that of HCP-Co, and phase transformation of the Co powder during repeated charge and discharge is discussed.

\section{Experimental}

Two Co powder samples were tested. Sample A was a commercial powder (Kokkola Chemicals) with a pure HCP structure prepared by a chemical precipitation method. Its electrochemical hydrogenation behavior was presented previously [18], and is used here as a control specimen. Sample B with an FCC structure was fabricated by an arc discharge method, as was presented previously [20]. The cyclic voltammetry (CV) was conducted by using a threeelectrode test cell. The cell consisted of sample A or B as the working electrode, sintered $\mathrm{Ni}(\mathrm{OH})_{2}$ powder as the counter electrode, and an $\mathrm{Hg} / \mathrm{HgO}$ electrode as the reference electrode. The electrolyte was $6 \mathrm{M} \mathrm{KOH}+1 \mathrm{wt} \% \mathrm{LiOH}$. The scan range was between $-1.3 \mathrm{~V}$ and $-0.5 \mathrm{~V}$ vs. $\mathrm{Hg} / \mathrm{HgO}$, and the scan started from the open circuit potential and then along the negative direction at a scan rate of $5 \mathrm{mV} / \mathrm{s}$. The electrochemical charge and discharge curves were measured in a two-electrode test cell, which contained one piece of positive electrode and one piece of negative electrode made of Co powder. The positive electrode material consisted of nickel hydroxide, $5 \mathrm{wt} \% \mathrm{Co}$, and $5 \mathrm{wt} \% \mathrm{CoO}$. The electrolyte was $6 \mathrm{M}$ $\mathrm{KOH}+1 \mathrm{wt} \% \mathrm{LiOH}$. Each of the positive and negative electrode material was mixed with 3 wt\% PTFE to form a paste, and coated on a piece of Ni-foam. The electrode plate was cold pressed at a pressure of $50 \mathrm{kgf} / \mathrm{cm}^{2}$ for $30 \mathrm{~s}$. Both the charge and the discharge currents were set at $10 \mathrm{~mA}$, and the cut-off voltage was $900 \mathrm{mV}$. The charge time was $1 \mathrm{~h}$ or $2 \mathrm{~h}$. All the experiments were conducted at $25^{\circ} \mathrm{C}$.
The crystalline structure or phase change of the samples before and after the charge/discharge test was identified by Xray diffraction (XRD) with a $\mathrm{Cu} \mathrm{K} \alpha$ source. The morphologies of the samples were examined by field emission scanning electron microscopy (FESEM) and transmission electron microscopy (TEM).

\section{Results and discussion}

\subsection{Characterization of Co powders}

Fig. 1 shows the XRD patterns of samples A and B. It can be seen that these two samples have the pure HCP and FCC structures. The particle size of sample A calculated by Scherrer's equation is $\sim 30 \mathrm{~nm}$. From the SEM micrographs displayed in Fig. 2 it is seen that the particles of sample A are aggregated together to form clusters in a size of $300-500 \mathrm{~nm}$. On the other hand, particles of sample $B$ with the size of approximately $30-50 \mathrm{~nm}$ are separated very well. The TEM micrograph for a large particle, Fig. 2(c), shows clearly that there are several graphite layers covering the surface of the particle, although the graphite peak is not observed in the XRD pattern. The graphite content in this nanocapsulated structure measured by thermal decomposition at $700{ }^{\circ} \mathrm{C}$ for $45 \mathrm{~min}$ was approximately $8.0 \mathrm{wt} \%$.

\subsection{Electrochemical hydrogenation}

Fig. 3 shows the cyclic voltammetric curves of the two Co samples in the 20th scan. For sample A, a broad anodic current peak centered at $-0.72 \mathrm{~V}$ is observed. In the cathodic scan, a peak at near $-1.12 \mathrm{~V}$ can only be barely seen. Such a behavior has been reported for ultrafine amorphous Co-B and crystalline Co-P particles [16,21]. For sample B, a pair of anodic and cathodic current peaks at $-0.78 \mathrm{~V}$ and $-1.10 \mathrm{~V}$, respectively, is noted. The more negative anodic peak and more pronounced cathodic peak might be due to the encapsulation of graphite. The anodic peaks of samples A and B are similar to the cyclic voltammetric feature of hydrogen storage electrodes [14-16,21], and are ascribed to the electrochemical

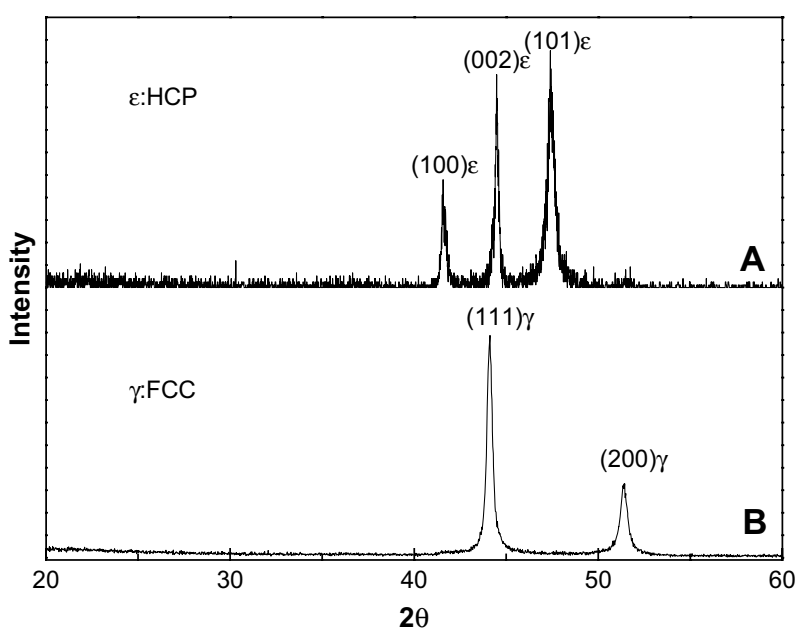

Fig. 1 - XRD patterns of the two Co powders. 

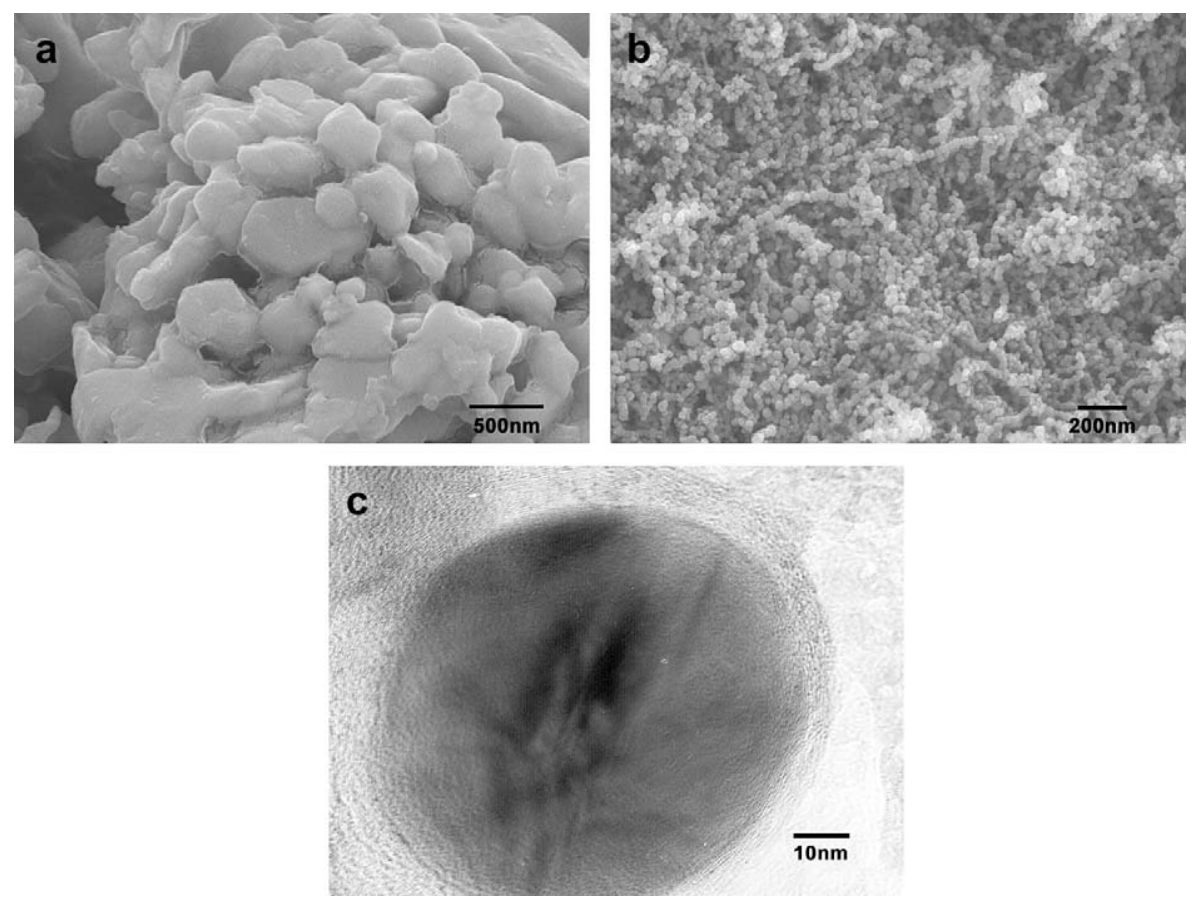

Fig. 2 - (a) SEM micrograph of sample A, (b) SEM micrograph of sample B, and (c) TEM image of an individual particle of sample $B$.

oxidation of adsorbed hydrogen. As for the cathodic peak at near $-1.10 \mathrm{~V}$, it is generally attributed to the electrochemical reduction of $\mathrm{H}_{2} \mathrm{O}$, i.e., hydrogen adsorption on the electrode. The cyclic voltammetric results for the two samples demonstrate that the two samples undergo similar electrochemical hydrogenation and dehydrogenation processes.

Fig. 4 shows the discharge capacities of samples A and B. The discharge capacities of sample $B$ have already been normalized with $92 \mathrm{wt} \% \mathrm{Co}$. It is observed that the activation rate of sample A is faster than, but the cycle stability is not as good as, that of sample $B$. The slower activation rate and better stability of sample B may be due to the graphite layers

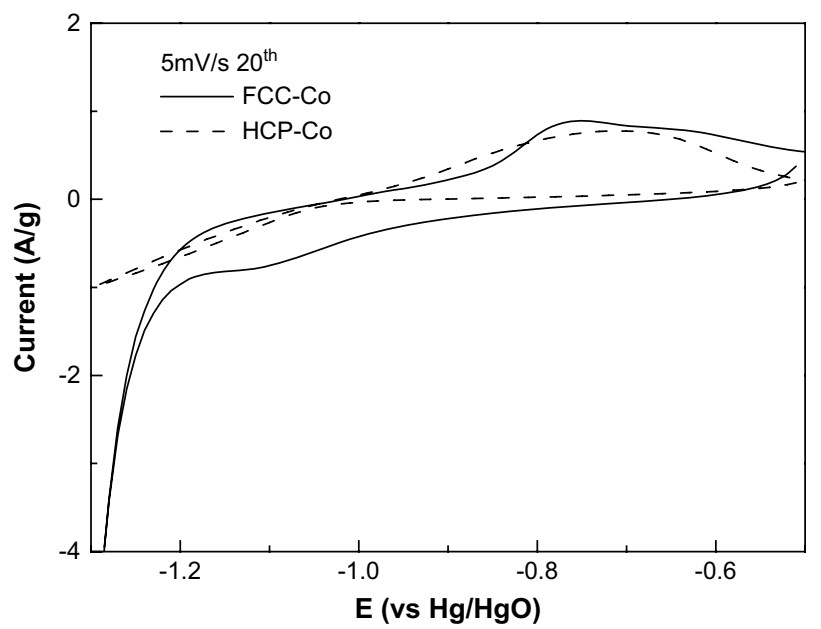

Fig. 3 - CV curves of the two Co samples in $6 \mathrm{M} \mathrm{KOH}$ solution. Scan rate: $5 \mathrm{mV} / \mathrm{s}$. covered on the surface. The discharge capacity of sample A increases to a maximum value and then gradually decays. For sample B, the capacity steadily increases as the cycle number increases and then remains very stable. Both samples have almost the same discharge capacity of $350 \mathrm{mAh} / \mathrm{g}$ (equivalent to $\mathrm{H} / \mathrm{Co}=1.29 \mathrm{wt} \%$ or $\mathrm{CoH}_{0.77}$ ) after 30 cycles of test, with the charge for either $1 \mathrm{~h}$ or $2 \mathrm{~h}$, regardless of different structures in the initial state. Compared with commercial $\mathrm{AB}_{5}$-type hydrogen storage alloys, they have a higher discharge capacity. With regard to the continual decay in discharge capacity of sample A, graphite encapsulation of the nanocrystalline sample B appears to have a significant impact on its cycle stability. Since a high concentration of $\mathrm{KOH}(6 \mathrm{M})$ was used as the electrolyte, the electrode materials might be attacked during the repeated charge/discharge test. For example, the main cause of decay in discharge capacity of $\mathrm{AB}_{5}$-type electrode is pulverization and oxidation of the electrode material. As it will be shown in the subsequent section, some $\mathrm{Co}(\mathrm{OH})_{2}$ was present in both the samples, but the amount was smaller in sample B. This implies that the graphite layer covered on the Co surface is beneficial to corrosion resistance of sample $\mathrm{B}$ in the electrolyte, which improves the cycle stability.

Fig. 5a shows the electrochemical charge and discharge potential curves of the two samples in the first cycle at a constant current of $500 \mathrm{~mA} / \mathrm{g}$. The potential curves are basically very similar to those of metal hydrides. Two plateaus are observed for sample A during the charge, whereas the potential gradually increases to a plateau value for sample $B$. The cell voltages drop to $1.3 \mathrm{~V}$ and $1.35 \mathrm{~V}$ for samples $\mathrm{A}$ and $\mathrm{B}$, respectively, when the charge current is stopped for a rest. The discharge plateaus of samples A and B are between $1.26 \mathrm{~V}$ 


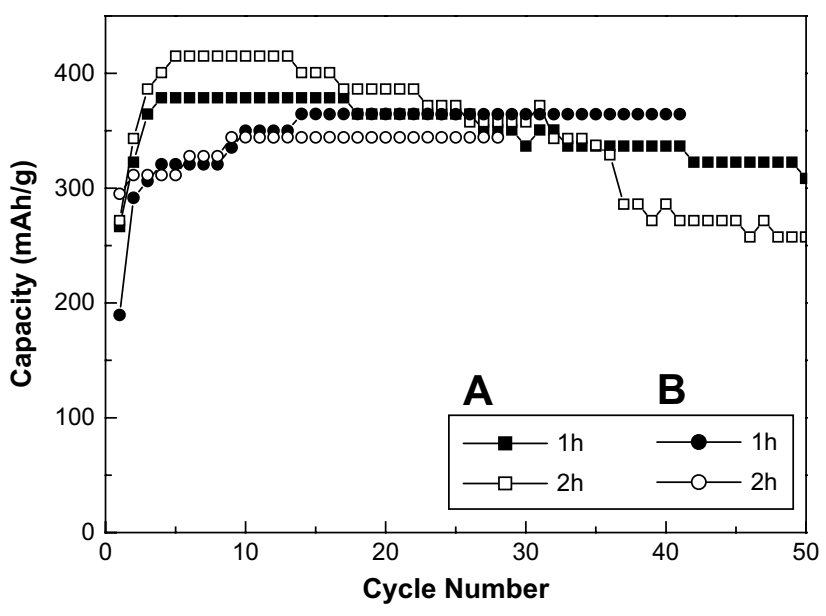

Fig. 4 - Discharge capacities of the two Co powders.
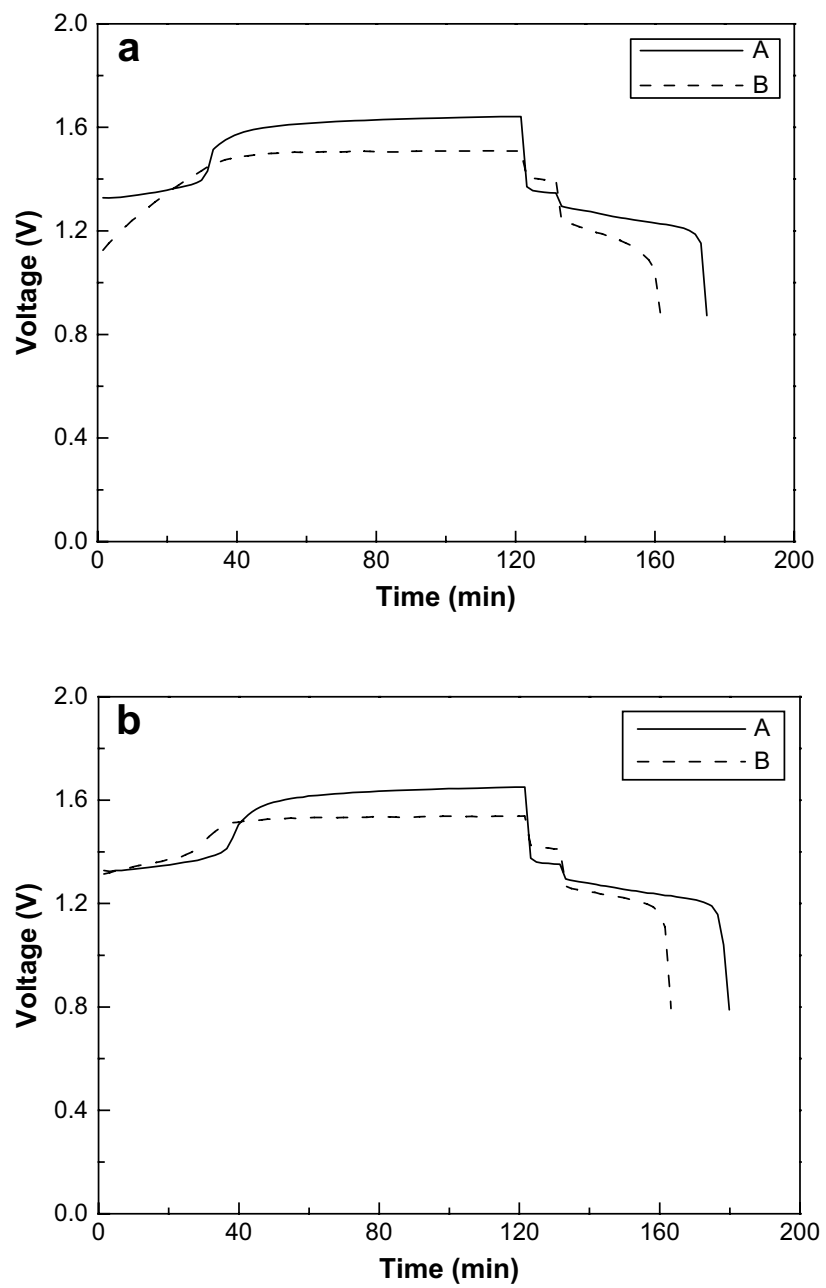

Fig. 5 - Electrochemical charge and discharge curves of the two Co samples at two different cycles. The samples are charged for $120 \mathrm{~min}$, rested for $10 \mathrm{~min}$ and then discharged to a cut-off potential of $0.9 \mathrm{~V}$. (a) First cycle and (b) fifth cycle. and $1.15 \mathrm{~V}$, comparable to those of $\mathrm{AB}_{2}$-type and $\mathrm{AB}_{5}$-type alloys. In general, the discharge plateaus of $A B_{2}$-type and $A B_{5}$ type alloys are between $1.3 \mathrm{~V}$ and $1.2 \mathrm{~V}$ and between $1.3 \mathrm{~V}$ and $1.1 \mathrm{~V}$, respectively [22]. Therefore, the discharge capacity can be attributed to the desorption of hydrogen from $\mathrm{Co}$, and clearly sample B exhibits a lower discharge capacity than sample A in the first cycle.

The potential curves of both the samples in the fifth cycle are displayed in Fig. 5b. The overall charge and discharge characteristics are basically similar to those of the first cycle, except that sample $B$ also exhibits two plateaus in the charge stage. Based on the charge potential curves, it is postulated that the first plateau of sample A in Fig. $5 \mathrm{a}$ is due to the hydrogenation of the HCP phase, and transformation to the FCC phase occurs after approximately $35 \mathrm{~min}$ of charging. The second plateau then stands for the charging behavior of the FCC phase. On the other hand, in Fig. 5a, sample B immediately starts to hydrogenate in the first cycle in the form of FCC phase. In the fifth cycle, the initial phases of both the samples are the same (i.e., HCP phase), which leads to similar features of charge potential curve. The lower charge potential of sample B might be due to the graphite encapsulation.

\subsection{Phase transformation}

The XRD patterns of both the samples after repeated charge are shown in Fig. 6. It is seen that both patterns are essentially the same. Since the peaks of FCC-Co are overlapped with those of Ni-foam, it is difficult to distinguish the phase transformation between HCP-Co and FCC-Co during the electrochemical charge/discharge cycling. The presence of FCC-Co has been demonstrated, however, by using a pellet prepared by the HCP-Co and Cr powders, as was discussed in a previous work [18]. There is only a very small amount of HCP-Co left, even for sample A, which implies that most HCPCo has transformed to FCC-Co and the FCC-Co is the major phase for discharge in both samples. This explains why both samples exhibit about the same discharge capacities. Although the $\mathrm{Co}(\mathrm{OH})_{2}$ peaks are also observed, the intensity is not very strong. The formation and effect of this phase on the hydrogenation properties have been discussed previously $[18,23]$.

Combined with the result of electrochemical potential curves, it is clear that the phase transformation between HCPCo and FCC-Co takes place which results in the high discharge capacities. In a previous work, it was revealed that both $\mathrm{CoO}$ and $\mathrm{Co}_{3} \mathrm{O}_{4}$ could also be electrochemically hydrogenated and dehydrogenated, and similar discharge capacities to that of $\mathrm{HCP}-\mathrm{Co}$ were obtained [23]. Because $\mathrm{CoO}$ and $\mathrm{Co}_{3} \mathrm{O}_{4}$ were mostly reduced to HCP-Co in the initial charge stage, the discharge capacities of both oxides came mainly from dehydrogenation of $\mathrm{CoH}_{x}$. The present study reaffirms that the reaction sequence of $\varepsilon$ - $\mathrm{Co} \rightarrow \varepsilon-\mathrm{CoH}_{x} \rightarrow \gamma-\mathrm{CoH}_{x}$ is the key for the electrochemical charge/discharge of Co or Co-containing compounds.

Finally, the role and application of Co in hydrogen energy is commented. As it is known, Co is expensive. Generally, partial replacement of $\mathrm{Ni}$ with $\mathrm{Co}$ to reduce volume expansion of $\mathrm{AB}_{5}-$ type materials is widely used. As was mentioned previously, the formation of hydrides of Co is very difficult under 

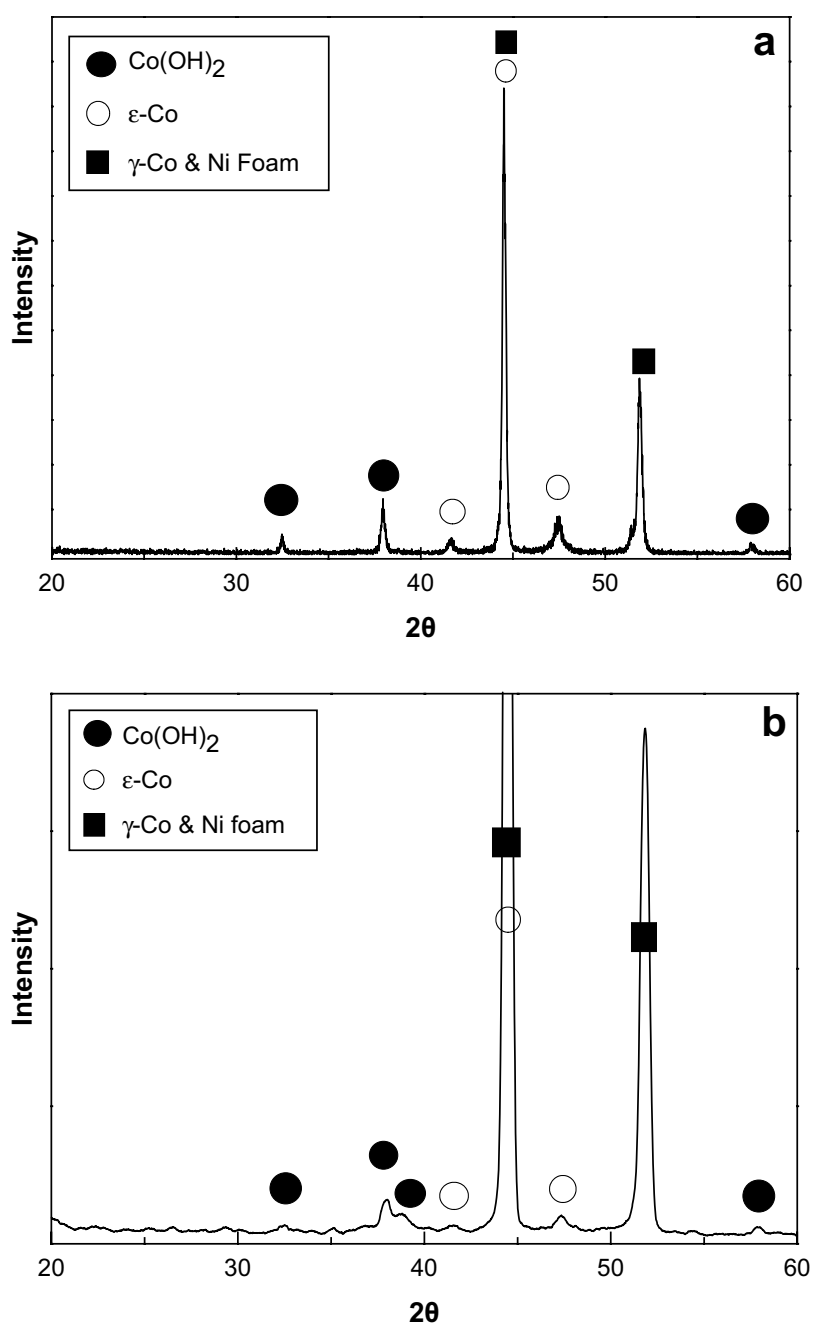

Fig. 6 - XRD patterns of the two Co samples after repeated charge. (a) HCP-Co and (b) FCC-Co.

gas-phase hydrogenation. It needs a very high hydrogen pressure to get the maximum hydrogenation capacity of Co. This study shows that a high reversible hydrogen storage capacity of Co can be achieved by electrochemical chargedischarge at room temperature. The ability for hydrogenation by charge-discharge of Co was observed only until recent years [14-16,21]. This implies that nanocrystalline Co has potentials to be a good catalyst for hydrogen just like other materials with a high specific surface area (e.g., CNT, etc.). In addition, the present work together with previous studies $[18,23]$ has also demonstrated that Co plays multifunctional roles by adding to the typical $\mathrm{AB}_{5}$-type electrodes, i.e., catalyst, reduction of expansion, and hydrogen absorption.

\section{Conclusion}

Graphite encapsulated nanocrystalline Co powder with an FCC structure was used as the negative electrode in an alkaline solution, and its electrochemical hydrogenation behavior was studied and compared with that of HCP-Co. Both the samples have about the same stabilized discharge capacity of $350 \mathrm{mAh} / \mathrm{g}$ (equivalent to $\mathrm{H} / \mathrm{Co}=1.29 \mathrm{wt} \%$ or $\mathrm{CoH}_{0.77}$ ). The discharge capacities of these two structures of Co are attributed to the $\mathrm{CoH}_{x} / \mathrm{Co}$ dehydrogenation reaction. The reversible phase transformation between the HCP and FCC phases during electrochemical hydrogenation is observed for both the samples, which results in the high discharge capacities. Graphite encapsulation is beneficial to cycle stability of the FCC powder.

\section{Acknowledgments}

This work was supported by the Ministry of Education of Taiwan under contract A-91-E-FA04-1-4 and the Ministry of Economic Affairs under contract 93-EC-17-A-08-S1-0003.

\section{R E F E R E N C E S}

[1] Senoh H, Kiyobayashi T, Kuriyama N. Hydrogen electrode reaction of lithium and sodium aluminum hydrides. Int $\mathrm{J}$ Hydrogen Energy 2008;33:3178-81.

[2] Palumbo O, Paolone A, Cantelli R, Chandra D. Lithium nitride as hydrogen storage material. Int J Hydrogen Energy 2008;33: 3107-10.

[3] Liu YY, Zeng JL, Zhang J, Xu F, Sun LX. Improved hydrogen storage in the modified metal-organic frameworks by hydrogen spillover effect. Int J Hydrogen Energy 2007;32: 4005-10.

[4] Ndungu P, Nechaev A, Khotseng L, Onyegebule N, Davids W, Mohammed R, et al. Carbon nanomaterials synthesized using liquid petroleum gas: analysis toward applications in hydrogen storage and production. Int J Hydrogen Energy 2008;33:3102-6.

[5] Khoshnevisan B, Behpour M, Ghoreishi SM, Hemmati M. Absorptions of hydrogen in Ag-CNTs electrode. Int J Hydrogen Energy 2007;32:3860-3.

[6] He G, Jiao L, Yuan H, Zhang Y, Zhang Y, Wang Y. Effect of synthesis method on the structure and electrochemical behaviour of Co-Si particles. Int J Hydrogen Energy 2007;32: 3416-9.

[7] Zhang Y, Jiao L, Yuan H, Zhang Y, Liu L, Wang Y. Effect of Si on electrochemical hydrogen storage properties of crystalline Co. Int J Hydrogen Energy 2008;33:1317-22.

[8] Khaldi C, Mathlouthi H, Lamloumi J, Percheron-Guégan A. Electrochemical study of cobalt-free $\mathrm{AB}_{5}$-type hydrogen storage alloys. Int J Hydrogen Energy 2004;29:307-11.

[9] Shu K, Zhang S, Lei Y, Lú G, Wang Q. Study on structure and electrochemical performance of melt-spun nonstoichiometry alloys $\mathrm{Ml}(\mathrm{NiCoMnTi})_{5+\mathrm{x}}$. Int J Hydrogen Energy 2003;28:1101-5.

[10] Seo CY, Choi SJ, Choic J, Park CN, Lee JY. Effect of vanadium content on electrochemical properties of La-based $A_{5}$-type metal hydride electrodes. Int J Hydrogen Energy 2003;28: 967-75.

[11] Feng F, Geng M, Northwood DO. Electrochemical behaviour of intermetallic-based metal hydrides used in $\mathrm{Ni} /$ metal hydride (MH) batteries: a review. Int J Hydrogen Energy 2001; 26:725-34.

[12] Miao H, Pan H, Zhang S, Chen N, Li R, Gao M. Influences of Co substitution and annealing treatment on the structure and electrochemical properties of hydrogen storage alloys $\mathrm{La}_{0.7} \mathrm{Mg}_{0.3} \mathrm{Ni}_{2.45-x} \mathrm{Co}_{0.75+x} \mathrm{Mn}_{0.1} \mathrm{Al}_{0.2}(x=0.00,0.15,0.30)$. Int J Hydrogen Energy 2007;32:3387-94. 
[13] Endo D, Sakaki K, Akiba E. Lattice expansion for $\mathrm{MmNi}_{4.30-x} \mathrm{Co}_{x} \mathrm{Al}_{0.30} \mathrm{Mn}_{0.40}(x=0,0.75)$ studied by in situ X-ray diffraction. Int J Hydrogen Energy 2007;32:3435-41.

[14] Mitov M, Popov A, Dragieva I. Nanoparticles produced by borohydride reduction as precursors for metal hydride electrodes. J Appl Electrochem 1999;29:59-63.

[15] Mitov M, Popov A, Dragieva I. Possibilities for battery application on $\mathrm{Co}_{x} \mathrm{~B}_{y} \mathrm{H}_{z}$ colloid particles. Colloids Surf A 1999; 149:413-9.

[16] Wang YD, Ai XP, Yang HX. Electrochemical hydrogen storage behaviors of ultrafine amorphous Co-B alloy powder. Chem Mater 2004;16:5194-7.

[17] Feng Y, Jiao L, Yuan H, Zhao M. Effects of amorphous CoB on the structural and electrochemical characteristics of MgNi alloy. Int J Hydrogen Energy 2007;32:2836-42.

[18] Chung SR, Wang KW, Perng TP. Electrochemical hydrogenation of crystalline Co. J Electrochem Soc 2006;153: A1128-31.
[19] Antonov VE, Antonova TE, Baier M, Grosse G, Wagner FE. On the isomorphous phase transformation in the solid f.c.c. solution Co-H at high pressures. J Alloys Compd 1996;239: 198-202.

[20] Elliott BR, Host JJ, Dravid VP, Teng MH, Hwang JH. A descriptive model linking possible formation mechanisms for graphite-encapsulated nanocrystals to processing parameters. J Mater Res 1997;12:3328-44.

[21] Cao Y, Zhou W, Li X, Ai X, Gau X, Yang H. Electrochemical hydrogen storage behaviors of ultrafine Co-P particles prepared by direct ball-milling method. Electrochim Acta 2006;51:4285-90.

[22] Hong $\mathrm{K}$. The development of hydrogen storage alloys and the progress of nickel hydride batteries. J Alloys Compd 2001;321: 307-13.

[23] Chung SR, Wang KW, Sheen SR, Yeh CT, Perng TP. Electrochemical reduction and hydrogenation of Co oxides. Electrochem Solid State Lett 2007;10:A155-8. 